\title{
Re-evaluation of the value of adjunctive modern radiotherapy in muscle-invasive bladder cancer
}

\author{
Mohamed Saad Zaghloul \\ Radiation Oncology Department, Children Cancer Hospital, Egypt and National Cancer Institute, Cairo University, Cairo, \\ Egypt
}

Correspondence: Mohamed Saad Zaghloul. Address: Radiation Oncology Department, Children Cancer Hospital, Egypt and National Cancer Institute, Cairo University, Cairo, Egypt. Telephone: 20-100-1720-664. E-mail: mszagh@yahoo.com

Received: January 14, 2012

Accepted: May 1, 2012

Published: June 1, 2012

DOI : $10.5430 /$ jst.v2n3p1

URL: http://dx.doi.org/10.5430/jst.v2n3p1

A controlled prospective randomized study was recently published; comparing pre-and post-operative radiotherapy in bladder cancer patients ${ }^{[1]}$. This study was the first to compare these radical cystectomy adjunctive radiation methods. For decades left, both pre-and post-operative radiotherapy in bladder cancer had negative image for genitourinary oncologists. This unsatisfactory image was either due to insignificant improvement in the published survival rates or due to the fear of high and unacceptable late complications ${ }^{[2]}$. Abd El-Moneim et al. ${ }^{[1]}$ achieved 5-year overall survival of $51 \%$ as $89 \%$ of their patients belonged to the clinical categories T3 and T4. They showed clearly that there was no difference between the 2 randomized groups; in overall survival, disease-free survival, local control and distant metastasis-free rates. It was clear from their results that both immediate postoperative complications and late serious gasterointestinal (GIT) sequalae were similar in both groups and of minimal amplitude. Late bowel complications were reported to be $4.5 \%$ in the post-operative setting and $2 \%$ in the pre-operative setting this was nearly similar to the percentages reported previously by Zaghloul et al. ${ }^{[3]}$ who reported $4 \%$ and $5 \%$ grade $3+4$ late bowel toxicity in conventional and hyper fractionated postoperative radiotherapy groups. In another retrospective study, a total of $12 \%$ of the patients who received PORT experienced chronic intestinal complications of different grades compared with $8 \%$ in the cystectomy alone group. There were four patients in each group (5.8\% and 3.3\%, respectively) that needed surgery for intestinal late complications ${ }^{[4]}$. On the other hand, much higher late GIT complications were reported by Reseinger et al. ${ }^{[5]}$. They experienced 37\% late GIT complications with $22.5 \%$ of the irradiated patients suffered from grade $3+4$ and required surgery though having similar survival rates to that of Zaghloul et al. ${ }^{[3]}$. Such alarming and hindering results were mainly due to the usage of unusually large volume of irradiation to include the common iliac and lower para-aortic lymph nodes. The safe and similarly effective irradiation volume restricted in its upper limit to include the internal and external iliac nodes (Just below the bifurcation of the common iliac vessels) ${ }^{[2]}$. This big difference in radiation volume led to the discrepancy in the reported late GIT and therefore the hesitancy of the oncology community to re-investigate the value of post-operative radiotherapy after radical cystectomy. Obviously, Abd El-Moneim et al. ${ }^{[1]}$ emphasized the previously reported mild complication rates ${ }^{[2-4]}$ and concluded that pre-and post-operative radiotherapy was tolerable and safe. This report though being the first comparing these 2 modalities of radiation, yet it used a conventional 2D technique with 3 fields arrangement. This conventional technique entails bigger volume of intestine to be exposed to high radiation dose; being unable to conform the planning volume and minimize the dose to the organs at risk (OAR). Essentially this technique does not necessitate the use of any type of verification (Port film, Electronic Portal Imaging Device EPID or Cone-beam Computed Tomography CBCT). It is well known that the bladder cancer has a significant target motion, necessitating the use of margins to account for this. The continuous bladder filling leads to shape and volume changes. In contrast to prostate cancer, information regarding the calculation of internal margins in bladder cancer irradiation is sparse. However, the population-based estimation of 
margins of $1.5 \mathrm{~cm}$ may be inadequate to account for bladder motion in up to $65 \%$ of patients ${ }^{[6,7]}$. Bladder wall movement of more than $1.5 \mathrm{~cm}$ occurred at least once in $60 \%$ of patients with a maximum displacement of $2.7 \mathrm{~cm}{ }^{[8]}$. In $33 \%$ of patients this compromised the treatment margin. Furthermore, Pos et al. ${ }^{[6]}$ showed that the gross tumor volume (GTV) still fell outside the planning target volume (PTV) at least once in $65 \%$ of patients. Harris and Buchanan ${ }^{[7]}$ demonstrated that $40 \%$ of patients had bladder wall movement more than $1 \mathrm{~cm}$, up to a maximum of $2.5 \mathrm{~cm}$, and that this resulted in bladder movement outside the treatment volume in $20 \%$ of cases. Bladder wall displacement of more than $15 \mathrm{~mm}$ in $40 \%$ of patients, with a maximum displacement of up to $29-36 \mathrm{~mm}$ was reported in one study ${ }^{[9]}$. A large variation in the urinary inflow rate among individuals was illustrated by Lotz et al. ${ }^{[10]}$. This variation ranged from 2.1 to $15 \mathrm{~mL} / \mathrm{min}$ (Mean: $9 \pm 3$ $\mathrm{mL} / \mathrm{min})$. McBain et al. ${ }^{[11]}$ assessed the intra-fractional bladder movement using serial MR scans and demonstrated volume increase of $19 \%-108 \%$ associated with wall movement of up to $2.0 \mathrm{~cm}$ occurring over a 28 -min timeframe. It was estimated that the greatest bladder motion occurs in the superior direction and at the bladder dome. Large movements are also observed in the anterior and posterior directions, with the least motion at the inferior boundaries of the bladder ${ }^{[12]}$. This magnitude of errors due to organ motion, suggested that anisotropic GTV-CTV margins should be used. Furthermore, The CTV to PTV margin had to be at least $1 \mathrm{~cm}$ in any direction ${ }^{[13]}$. Moreover, Meijer et al. reported the need of $2 \mathrm{~cm}$ in cranial direction, $1.0 \mathrm{~cm}$ in the caudal, $0.7 \mathrm{~cm}$ in the right and left directions, $0.7 \mathrm{~cm}$ in the anterior and $1.3 \mathrm{~cm}$ in the posterior direction ${ }^{[14]}$. On the other hand, Muren et al. ${ }^{[9]}$ computed these values as $2.3 \mathrm{~cm}$ for anterior and $1.8 \mathrm{~cm}$ for the posterior directions. It is worth noting that these margins are related to an empty bladder, as this is more reproducible and more comfortable for the patient. Advances in CBCT technology have led to the ability to view real-time images of soft tissue and have allowed more precise verification of positioning. CBCT has been studied in bladder radiotherapy as part of an online plan selection strategy (Adaptive radiotherapy) guided by the CBCT soft tissue delineation. This process may lead to determining the patient-specific CTV-PTV margin using the first few CBCT ${ }^{[15]}$. Moreover, the volume resulted from patient-specific margin was consistently smaller than PTV after adding the usually adopted $2 \mathrm{~cm}$ margin isotropically around the CTV, but with equivalent target coverage. Cyber knife, through tumor tracking characteristics offered a safe decrease in CTV and PTV margins, limiting the OAR volumes that received significantly high doses and optimizing the dose-volume histograms ${ }^{[16]}$. On-treatment CBCT is usually able to give sufficient resolution to visualize the bladder. Fiducial markers can be visualized using EPID for IGRT ${ }^{[17]}$ or to aid GTV delineation when considering focal boost. Cystoscopically inserted lipidol was used to aid tumor delineation and for IGRT ${ }^{[18]}$. Obviously, the problem of bladder movement and filling is not applicable in post-operative radiotherapy setting. Although, it is recommended to follow the surgical clips determining the tumor bed and the removed nodal volume, yet the policy of delineation with the aid of a fused pre-operative CT to determine the empty bladder volume is highly advisable ${ }^{[2]}$. The adoption of the more recent techniques of conformal, IMRT or adoptive radiotherapy is expected to improve the results tremendously both in terms of survival and OAR toxicity minimization. We are still in need of more studies to compare pre-and post-operative radiotherapy to radical cystectomy alone for muscle-invasive bladder cancer using the modern radiotherapy planning and verification techniques. Careful evaluation of late toxicities in the 3 randomized groups will be of utmost importance in clearing the myth of deadly high morbidity of post-cystectomy radiation therapy that was mainly related the larger volume and less precise technique of irradiation.

\section{References}

[1] Abd El-Moneim H, El-Baradie MM, Younis A et al. A prospective randomized trial for preoperative versus postoperative adjuvant radiotherapy for muscle-invasive bladder cancer. Urol Oncol 2011; doi:10.1016/j.urolonc.2011.01.008. PMid:21353794 http://dx.doi.org/10.1016/j.urolonc.2011.01.008

[2] Zaghloul MS. Adjuvant and neoadjuvant radiotherapy for bladder cancer: Revisited. Future Oncol 2010;6:1177-91. PMid:20624129 http://dx.doi.org/10.2217/fon.10.82

[3] Zaghloul MS, Awwad HK, Omar S, et al. Postoperative radiotherapy of carcinoma in bilharzial bladder: Improved disease-free survival through improving local control. Int J Radiat Oncol Biol Phys 1992;22:511-17. http://dx.doi.org/10.1016/0360-3016(92)90005-3

[4] Zaghloul MS, Nouh A, Nazmy M, et al. Long-term results of primary adenocarcinoma of the urinary bladder. A report on 192 patients. Urol Oncol 2006;24:13-20. PMid:16414487 http://dx.doi.org/10.1016/j.urolonc.2005.05.027 
[5] Reisinger S, Mohiuddin M, Mulholland S. Combined pre-and postoperative adjuvant radiation therapy for bladder cancer-A 10-year experience. Int J Radiat Oncol Biol Phys 1992;24:463-68. http://dx.doi.org/10.1016/0360-3016(92)91060-Z

[6] Pos FJ, Koedooder K, Hulshof MC et al.: Influence of bladder and rectal volume on spatial variability of a bladder tumor during radical radiotherapy. Int. J. Radiat. Oncol. Biol. Phys. 2003;55(3):835-41. http://dx.doi.org/10.1016/S0360-3016(02)04158-5

[7] Harris SJ, Buchanan RB: An audit and evaluation of bladder movements during radical radiotherapy. Clin. Oncol. R. Coll. Radiol. 1998;10(4):262-64. http://dx.doi.org/10.1016/S0936-6555(98)80014-9

[8] Turner SL, Swindell R, Bowl N et al.: Bladder movement during radiation therapy for bladder cancer: Implications for treatment planning. Int. J. Radiat. Oncol. Biol. Phys.1997;39(2):355-60. http://dx.doi.org/10.1016/S0360-3016(97)00070-9

[9] Muren LP, Smaaland R, Dahl O: Organ motion, set-up variation and treatment margins in radical radiotherapy of urinary bladder cancer. Radiother. Oncol. 2003;69(3):291-304. http://dx.doi.org/10.1016/S0167-8140(03)00246-9

[10] Lotz HT, Pos FJ, Hulshof MC et al.: Tumor motion and deformation during external radiotherapy of bladder cancer. Int. J. Radiat. Oncol. Biol. Phys. 2006;64:1551-58. PMid:16580504 http://dx.doi.org/10.1016/j.ijrobp.2005.12.025

[11] McBain CA, Khoo VS, Buckley DL et al.: Assessment of bladder motion for clinical radiotherapy practice using cine-magnetic resonance imaging. Int. J. Radiat. Oncol. Biol. Phys. 2009;75(3):664-71. PMid:19473781 http://dx.doi.org/10.1016/j.ijrobp.2008.11.040

[12] Logue JP, Sharrock CL, Cowan RA et al.: Clinical variability of target volume description in conformal radiotherapy planning. Int. J. Radiat. Oncol. Biol. Phys. 1998;41(4):929-31. http://dx.doi.org/10.1016/S0360-3016(98)00148-5

[13] McBain CA, Logue JP: Radiation therapy for muscle-invasive bladder cancer: Treatment planning and delivery in the 21st Century. Semin. Radiat. Oncol. 2005;15(1):42-48 PMid:15662606 http://dx.doi.org/10.1016/j.semradonc.2004.07.015

[14] Meijer GJ, Rasch C, Remeijer P, Lebesque JV: Three-dimensional analysis of delineation errors, setup errors, and organ motion during radiotherapy of bladder cancer. Int. J. Radiat. Oncol. Biol. Phys. 2003;55(5):1277-87. http://dx.doi.org/10.1016/S0360-3016(02)04162-7

[15] TolanS, Kong V, Rosewall T. et al. Patient-specific PTV margins in radiotherapy for bladder cancer - A feasibility study using cone beam CT. Rdiother Oncol 2011;99(2):131-36. PMid:21620497 http://dx.doi.org/10.1016/j.radonc.2011.04.008

[16] Thariat J, Trimaud R, Angellier G et al. Innovative image-guided Cyber knife ${ }^{\circledR}$ stereotactic radiotherapy for bladder cancer. Br. J. Radiol. 2010;83, e118-21. PMid:20505025 http://dx.doi.org/10.1259/bjr/26397829

[17] Lalondrelle S, Thompson A, Khoo V. Fiducial markers in external beam radiotherapy for bladder cancer. Radiother Oncol 2007;85(2):324. PMid:17904669 http://dx.doi.org/10.1016/j.radonc.2007.08.011

[18] Waddell BE, Rodriguez-Bigas MA, Lee RJ, Weber TK, Petrelli NJ. Prevention of chronic radiation enteritis. J Am Coll Surg. 1999;189:611-24. http://dx.doi.org/10.1016/S1072-7515(99)00199-4 